\title{
Internet-specific epistemological beliefs and online information searching strategies of pre-service teachers: gender and department differences
}

\author{
F.Gizem Karaoğlan Yılmaz* \\ Bartin University, Department of Computer Education and Instructional Technology, Bartin, \\ Turkey
}

Ebru Kilıç Çakmak

Gazi University, Department of Computer Education and Instructional Technology, Ankara, Turkey

Article history

Received:

27.06.2016

Received in revised form: 23.07.2016

Accepted:

24.07.2016

Key words:

Pre-service teachers; Internetspecific epistemological beliefs; Online information searching strategies; Gender; Department.
With the wide use of internet, internet has become the easy and fast way of accessing information and one of the main sources used to access information. Especially with the spread of the use of Web 2.0 technologies, many internet users are now able to add/edit content on internet, shape it in a collaborative way on social environments and easily share it. Therefore, it is believed that there has been changes in the epistemological beliefs of internet users towards internet as a source of information. The purpose of this study is to examine internet-specific epistemological beliefs of pre-service teachers in terms of gender and department they study; and to reveal the impact internet-specific epistemological beliefs on online information searching strategies. The study group includes 203 pre-service teachers. For the collection of the data, personal information form, internet-specific epistemological beliefs and online information searching strategies inventory were used. The results of the study revealed that internet-specific epistemological beliefs did not change based on gender; yet there was a statistically significant difference based on department pre-service teachers study. In addition, it was also found that internet-specific epistemological beliefs did not have a significant impact on information searching strategies. And depending on the findings of the study, what could be done in the process of using internet-based information sources in education and teacher training programs were discussed and suggestions were made.

\section{Introduction}

Today, printed information sources are replaced with internet-based information sources and this caused to changes in the information searching behaviors of the individuals. There are a lot of media where individuals could make search on internet. Digital libraries, search engines, social networks, wikis, blogs, forums are among the leading ones. With the customization options that search engines and social networks offer to the users, people can

\footnotetext{
*Correspondence: gkaraoglanyilmaz@gmail.com
} 
get customized search results. Besides, such search alternatives as search on web, videos, news, images, maps makes it easier to search online. As a result of wide use of mobile device and internet that expanded with such features of web, people are able to access online information resources whenever and wherever they need.

While internet users guide the process of search while making search in online environments according to such factors as accessibility, ease of use, being familiar and the fact that it requires less time and effort, they might ignore such other factors as whether the accessed information is true and reliable, whether it fits their purpose and whether it is objective or not. Especially with the web 2.0 technology, users have become not only internet-literate individuals but individuals who contribute to and create content on internet. However, the risk here is that every internet-literate person could create and organize content on the web and that this contribution processes are not subject to an audit. So, people, either knowingly or unknowingly, people could add information to sources on internet whose reliability, validity and objectivity is arguable and they could cause internet users to get wrong information. Therefore, it is stated that internet-specific epistemological beliefs are important in accessing correct and reliable sources of information on internet and in organizing internet-based learning and information searching processes (Chiu, Liang, \& Tsai, 2013). Researchers indicate the importance of epistemological beliefs in understanding and constructing complex sources of information on internet which are controversial and include opposite viewpoints and contradictory information and which are not well-constructed (Bråten \& Strømsø, 2010; Kammerer, Bråten, Gerjets, \& Strømsø, 2013; Pieschl, Stahl, \& Bromme, 2008; Strømsø, Bråten, \& Samuelstuen, 2008; Tsai, Tsai, \& Hwang, 2011; Tu, Shih, \& Tsai, 2008).

\section{Epistemological Beliefs}

Perry (1981) defines epistemological beliefs as someone's points of views on the definition and sources of knowledge, the degree of its certainty, and its limitations and criteria (cited in. Muis, 2004). Schommer (1990) defines personal epistemological beliefs as individual's beliefs on what the knowledge is and how learning and knowledge happens. According to this, it is believed that those individuals, who believe that information is absolute, certain (right or wrong), is composed of individual unrelated pieces, something that is created by an authority and transferred to students, that learning ability is inborn and does not change, that an individual should learn a subject instantly or s/he can never learn it, are naïve. On the other hand, individuals who believe that information can not be absolute or certain, it could be either right or wrong depending on the context, that it is complicated formed of interrelated pieces, that it is formed by the individual through reasoning or experimental proofs, that learning ability can be improved and that learning depends on students' efforts, are sophisticated (Deryakulu, 2002).

Hofer and Pintrich (2002) indicate that it is necessary to better analyse epistemological beliefs and to explain its relationship with learning processes as the amount and accessibility of information increases and as the tools to access information change rapidly. Researchers indicate that Hofer and Pintrich's (2002) discourse should be separately considered for internet environment today and that due to such facts as the information sources are extremely heterogenous on internet, internet-specific epistemological beliefs should be examined (Bråten, Strømsø, \& Samuelstuen, 2005; Chiu et al., 2013; Kammerer et al., 2013; Strømsø \& Bråten, 2010). Moving from this, Bråten et al. (2005) developed internet-specific epistemological beliefs model based on Hofer and Pintrich's (1997) personal epistemological beliefs model. 


\section{Internet-Specific Epistemological Beliefs}

Internet-specific epistemological beliefs include individuals' beliefs towards the source of the information on the internet, on its accuracy, structure and on the evaluation of the information and information sources on this media (Strømsø \& Bråten, 2010; cited in: Kılıç Çakmak, Karaoğlan Yılmaz, \& Yılmaz, 2015). In Internet-Specific Epistemological Belief Scale developed by Strømsø and Bråten (2010), it is indicated that there are three main factors effecting internet-specific epistemological beliefs which are "certainty and source of knowledge", "justification for knowing" and "structure of knowledge" (Cited in. Kilıç Çakmak et. al., 2015).

Source of knowledge is based on the epistemological belief that the source of information can be created internally and effectively by the individual or that the source of information is presented from a center/authority and received that way by the individual. Certainty of knowledge, on the other hand, is based on the epistemological belief related to adaptation of the presented knowledge as it is without any changes or seeing the knowledge as something that can be changed and thus, making your own meaning out of what is presented. According to this, beliefs of the individuals related to sources of information on internet which can be grouped as certain-can not be changed or temporary-can be changed is grouped under this factor.

Justification for knowing factor incorporates the evaluation of information sources on internet in terms of reliability and validity through such ways as observation, questioning, assessment, comparing multiple sources and consulting the authority. This factor is based on the critical evaluation of information arguments on internet, checking it from multiple sources, reasoning and comparing it with prior knowledge.

Structure of knowledge factor incorporates the beliefs of the individuals towards the sources of knowledge on internet and the level of change in these beliefs. In other words, the structure of knowledge is a structure created by individuals' beliefs towards identifying the strengths and weaknesses of the individuals towards the sources of knowledge on internet. The beliefs of the individuals towards the aforementioned factors guide their internet-specific epistemological beliefs. Individuals could have either developed/mature beliefs or underdeveloped/immature beliefs towards each of these factors separately (Strømsø \& Bråten, 2010; Cited in. Kılıç Çakmak et. al., 2015)

\section{The Role of Internet-Specific Epistemological Beliefs in Online Information Searching}

According to Hartley and Bendixen (2001) epistemological beliefs could be efficient in the structuring process of the information sources accessed through internet. Chiu et al. (2013) indicate that epistemological beliefs of university students have a significant role in the context of internet-based academic search. Therefore, differences in epistemological beliefs could cause to differentiations in online information search processes and on deciding processes of information sources (Chiu et al., 2013; Mason, Ariasi \& Boldrin, 2011; Tu et al., 2008).

Those individuals with underdeveloped/immature internet-specific epistemological beliefs could have the tendency to accept source of knowledge on internet without evaluating and criticizing it in terms of such factors as correctness, reliability and validity. Therefore, 
teachers should ensure that learners' internet-specific epistemological beliefs of the learners reach a sophisticated level. This will enable learners to have a critical and sceptical point of view towards internet. In addition, teachers should also contribute to the development of effective online searching skills of the students. To do all abovementioned, it is believed that the level of teachers' internet-specific epistemological beliefs and online information search strategies will play a significant role. This attitude of the teachers will reflect on the students as well. Depending on their own epistemological beliefs teachers will either not consider all kinds of information students access on internet convenient or will consider any kind of information found on internet as sufficient. Therefore, first it is important to look into the internet-specific epistemological beliefs of teachers.

From a different standpoint, internet and information sources on internet are important tools in forming such learning contents and materials as the texts, images, graphics, animations, video and presentations that teachers will use in their classes; planning course activities and course plans; forming assessment and evaluation practices and questions; ensuring professional development through such practices as distance learning and meeting curriculum requirements (Lee \& Tsai, 2005). However, because the standpoint of teachers with a naive level of internet-specific epistemological beliefs and those with a sophisticated level of internet-specific epistemological beliefs towards information and sources of information on internet could be different, it is believed that using internet in all these activities and for all these aforementioned purposes could change. What one wonders here is how internet-specific epistemological beliefs effect pre-service teachers' utilization of information and information sources on internet as well as information searching strategies. Because identifying the existing state among pre-service teachers will lead to creating policies and practices towards teacher training in the process of utilizing ICT as well as updating the existing ones. Researchers indicate that there are limited number of studies carried out on teachers and preservice teachers on this subject; and that there is a need for new studies carried out on online information searching of teachers and evaluation of information carried out on a big number of participants; and the factors effecting these behaviors of the teachers should be identified (Chiu et al., 2013; Tsai et al., 2011; Tu et al., 2008; Yang, 2005).

\section{The Purpose of the Study}

The purpose of this study is to determine internet-specific epistemological beliefs of pre-service teachers; to examine it based on gender and department they study and to reveal its impact on online information searching strategies.

Existing studies reveal that internet-specific epistemological beliefs play an important role on searching behaviors on internet and yet they reveal the need for new studies. One issue of concern on the topic is whether internet-specific epistemological beliefs have an impact on online information searching strategies that Tsai and Tsai (2003) presented to determine the cognitive and metacognitive profiles of individuals in the process of information searching on internet. According to Tsai and Tsai's (2003) framework online information searching strategies are divided into three domains: behavioural, procedural and metacognitive domains and these three domains incorporate seven basic information searching strategies which are disorientation, evaluation, purposeful thinking, selecting main ideas, trial and error, control and problem solving. It is believed that examining the impact of internet-specific epistemological beliefs on searching strategies and revealing the differences between the searching strategies of individuals with different belief levels will provide significant contributions to the discussions in the literature. Because although there are no researches 
looking into the relationship between internet-specific epistemological beliefs and search strategies in terms of effect, existing studies indicate interesting and contradictory findings on the impact of developed/mature epistemological beliefs on the self-regulation processes of individuals during internet-based learning and information searching processes (Chiu et al., 2013). For instance, Strømsø and Bråten (2010) indicates that self-regulation and strategy utilization conditions of individuals with developed epistemological beliefs could be different in internet-based learning environments compared to traditional learning environments and that individuals with developed epistemological beliefs may not use self-regulation strategies as expected. From this perspective, if the fact that sub-dimensions in Tsai and Tsai's (2003) framework addresses cognitive and metacognitive profiles of the individuals is taken into account, it is believed that this study will contribute to ambiguities and discussions related to self-regulation skills and strategies individuals showcase during internet-based learning and information searching.

Apart from the impact of internet-specific epistemological beliefs of pre-service teachers on online information searching strategies, one more topic of concern whether gender and departments pre-service teachers study have an impact on internet-specific epistemological beliefs. While in some researches aiming to examine individual epistemological beliefs of the students it is stated that epistemological beliefs could be considered independently from the department students study, (Bråten and Strømsø, 2005; Hofer, 2000; Muis, 2004; SchommerAikins, Duell and Hutter, 2005); in other studies, the importance of examining epistemological beliefs considering the department students study at is highlighted (Deryakulu and Büyüköztürk, 2005; Hammer, 1994; Palmer and Marra, 2004; Paulsen and Wells, 1998; Schommer, 1993; Strobel, Cernusca and Jonassen, 2004). While the issue of whether the field of study is a factor or not in individual epistemological beliefs continues, the thing that is of concern here is whether field of study shows a difference depending on the department pre-service teachers study at within the context of internet-specific epistemological beliefs. This is considered as an issue to be studied on internet-specific epistemological beliefs (Chiu et al., 2013; Tsai et al., 2011).

On the other hand, in some studies in which gender variable is considered in individual epistemological beliefs, it is seen that the epistemological beliefs of male and female students differ (Bråten and Strømsø, 2004; Deryakulu and Büyüköztürk, 2005) whilst in some other there is not a significant difference in epistemological beliefs based on gender (Hofer, 2000; Mason and Boscolo, 2004; Schommer, Crouse and Rhodes, 1992; Schommer-Aikins, Mau, Brookhart and Hutter, 2000; Strobel et al., 2004). Therefore, it is possible to say that the impact of gender in explaining the differences in individual epistemological beliefs is still a controversial issue. Besides, when the fact that there are studies which reveal that there are differences among female and male students in studies on computer and internet use (Jackson et al., 2010; Tsai and Tsai, 2010), whether gender have a significant impact on internetspecific epistemological beliefs is something that is of concern.

Based on the purpose and motives given above, in this study, answers to the following research questions are looked for:

a) What is the level of pre-service teachers depending on their scores from internetspecific epistomological belief scale and online information search strategies inventory?

b) Do the epistemological beliefs of pre-service teachers differ depending on gender? 
c) Do the epistemological beliefs of pre-service teachers differ depending on the department they study?

d) Do the internet-specific epistemological beliefs of pre-service teachers effect their online information search strategies?

\section{Method}

This section includes information on the research design, study group, data collection tool and analysis of the data.

\section{Research Design}

In order to reveal the internet utilization of pre-service teachers as a source of information, to find out their internet-specific epistemological beliefs and their online information searching strategies, survey research was used in this study. Survey research helps researchers describe an event or circumstance in the form they exist. The event or circumstance is defined in the conditions they happen and in the form they exist (Fraenkel \& Wallen, 2006).

\section{Study Group}

The study was carried out on 203 pre-service teachers studying at the faculty of education of a state university. Demographic information of the pre-service teachers are given in Table 1.

Table 1. Demographic data of the pre-service teachers

\begin{tabular}{|c|c|c|c|}
\hline Variable & Group & $N$ & $\%$ \\
\hline \multirow{2}{*}{ Gender } & Female & 141 & 69.5 \\
\hline & Male & 62 & 30.5 \\
\hline \multirow[t]{2}{*}{ Total } & & 203 & 100 \\
\hline & Freshman & 23 & 11.3 \\
\hline \multirow{3}{*}{ Grade } & Sophomore & 72 & 35.5 \\
\hline & Third grade & 36 & 17.7 \\
\hline & Fourth grade & 72 & 35.5 \\
\hline \multirow[t]{2}{*}{ Total } & & 203 & 100 \\
\hline & Computer Education and Instructional Technology (CEIT) & 64 & 31.5 \\
\hline \multirow{6}{*}{ Department } & Secondary School Maths Teaching (SSMT) & 46 & 22.7 \\
\hline & English Language Teaching (ELT) & 12 & 5.9 \\
\hline & High School Maths Teaching (HSMT) & 12 & 5.9 \\
\hline & Preschool Teaching (PT) & 14 & 6.9 \\
\hline & Psychological Services Teaching (PST) & 31 & 15.3 \\
\hline & Turkish Language Teaching (TLT) & 24 & 11.8 \\
\hline Total & & 203 & 100 \\
\hline
\end{tabular}

\section{Data Collection Tools}

Internet-Specific Epistemological Belief Scale was used to determine pre-service teachers' internet-specific epistemological beliefs. This scale was originally developed by 
Bråten et al. (2005) and revised by Strømsø and Bråten (2010). It was adapted into Turkish by Kılıç Çakmak et al. (2015). The scale's reliability and validity studies were conducted on university students; and the scale has three dimensions, which are certainty and source of knowledge, justification for knowing and the structure of knowledge, and 16 items. The items were presented on a 10-point likert type scale and ranged from "(1) I strongly disagree" and "(10) I strongly agree". The total high scores from the scale illustrates that students' internetspecific epistemological beliefs are at a naive level; whilst low scores from the scale illustrates that students' internet-specific epistemological beliefs are at a sophisticated level. Cronbach alpha internal coefficient of consistency for the whole scale was found as .81. The Cronbach alpha values for the dimensions of the internet-specific epistemological belief scale ranged between .85 and .93 . Four items under the justification for knowing dimension of the scale are reversely coded .64 and below scores from the internet-specific epistemological belief scale means that students' internet-specific epistemological beliefs are sophisticated whilst scores between 65-112 means their internet-specific epistemological beliefs are average; scores of 113 and over means internet-specific epistemological beliefs of the students are naive.

Online Information Searching Strategy Inventory developed by Tsai (2009) and adapted into Turkish by Aşkar and Mazman (2013), was used in determining online information searching strategies of the pre-service teachers in the study. Online information searching strategy inventory involves 25 items and seven factors which are disorientation, evaluation, purposeful thinking, selecting main ideas, trial and error, control and problem solving. It is a 6-point likert type scale and the answers range as given: " $1=$ Not like me at all", " $6=$ Very much like me". Four items in disorientation factor and one item in problem solving factor are coded reverse in the inventory. Cronbach's alpha coefficient for the whole scale is found as .91. The Cronbach's alpha coefficient for the factors in the scale range between .61 and .77 . The lowest score one can get from the inventory is 25 while the highest score is 150 . High score from the inventory corresponds to developed online information searching strategies.

Demographic Information Form was formed by the researchers of present study. The students were asked to answer the questions in relation to their department in which they are enrolled, and gender etc.

\section{Analysis of Data}

Whether the internet-specific epistemological beliefs and online information searching strategies scores of pre-service teachers Show a normal distribution was analyzed through skewness and kurtosis levels and histogram graphics. It was found that Skewness and kurtosis levels changed between -1 and +1 . The examined histogram graphics showed that the distribution was normal. So, t-test and ANOVA, which are both parametric tests, were used in analyzing the data. .05 significance level was used in significance tests in the study.

\section{Results}

Findings and interpretations regarding the purpose and research questions of the study are given below. 


\section{Findings on the scores of pre-service teachers from internet-specific epistemological beliefs and from online information searching strategies inventory}

Descriptive statistics showing pre-service teachers' internet-specific epistemological beliefs and their online information searching strategy levels, in line with the first research problem of the study, are presented in Table 2.

Table 2. Breakdown of the scores of pre-service teachers regarding their internet-specific epistemological beliefs and online information searching strategies

\begin{tabular}{|c|c|c|c|c|c|c|}
\hline Scale & $\begin{array}{l}\text { Number } \\
\text { of items }\end{array}$ & $\begin{array}{c}\text { Minimum } \\
\text { score }\end{array}$ & $\begin{array}{c}\text { Maximum } \\
\text { score }\end{array}$ & $X$ & $s d$ & $\bar{X} / k$ \\
\hline Internet-specific epistemological belief scale & 16 & 36.00 & 130.00 & 89.42 & 17.07 & 5.59 \\
\hline Certainty and source of knowledge & 8 & 14.00 & 80.00 & 50.21 & 13.60 & 6.28 \\
\hline Justification for knowing & 4 & 4.00 & 40.00 & 13.46 & 7.18 & 3.37 \\
\hline Structure of knowledge & 4 & 4.00 & 40.00 & 25.75 & 7.10 & 6.44 \\
\hline Online information searching strategy inventory & 25 & 64.00 & 149.00 & 113.60 & 17.03 & 4.54 \\
\hline Disorientation & 4 & 7.00 & 24.00 & 18.49 & 3.89 & 4.62 \\
\hline Evaluation & 4 & 8.00 & 24.00 & 18.12 & 3.43 & 4.53 \\
\hline Purposeful thinking & 4 & 7.00 & 24.00 & 17.91 & 3.55 & 4.48 \\
\hline Trial and error & 3 & 5.00 & 18.00 & 13.32 & 2.79 & 4.44 \\
\hline Selecting main ideas & 3 & 5.00 & 18.00 & 13.88 & 2.83 & 4.63 \\
\hline Control & 4 & 7.00 & 24.00 & 18.73 & 3.56 & 4.68 \\
\hline Problem solving & 3 & 5.00 & 18.00 & 13.15 & 2.69 & 4.38 \\
\hline
\end{tabular}

According to Table 2, while the total score average of pre-service teachers from internetspecific epistemological belief scale is 89.42 (5.59 over 10); their total score average from online information searching strategies inventory is 113.60 (4.54 over 6). Looking at these scores, it can be said that pre-service teachers' internet-specific epistemological beliefs are average or in order words not clear whilst their online information searching strategies are sophisticated. When we look into internet-specific epistemological beliefs scale in terms of its sub-scales, certainty and source of knowledge and structure of knowledge sub-scales were average or in other words, unclear; whilst justification for knowing was close to developed level. When we look into Online Information Searching Inventory it can be said that all subscales are high.

\section{Findings on internet-specific epistemological beliefs based on gender}

Descriptive statistics and t-test results on whether internet-specific epistemological beliefs differ based on gender, in line with the second research problem of the study, are presented in Table 3.

Table 3. Descriptive statistics of the scores of pre-service teachers from internet-specific epistemological beliefs scale depending on gender and anova test results

\begin{tabular}{cccccccc}
\hline $\begin{array}{c}\text { Subdimensions of internet-specific } \\
\text { epistemological belief scale }\end{array}$ & Gender & $N$ & $\bar{x}$ & sd & $d f$ & $t$ & $p$ \\
\hline Certainty and source of knowledge & Female & 141 & 49.85 & 13.95 & 201 & -.561 & .575 \\
& Male & 62 & 51.02 & 12.85 & & & \\
& Female & 141 & 13.34 & 7.41 & 201 & -.366 & .714 \\
Justification for knowing & Male & 62 & 13.74 & 6.66 & & & \\
& Female & 141 & 25.82 & 7.43 & 201 & .202 & .840 \\
Structure of knowledge & Male & 62 & 25.60 & 6.35 & & & \\
& Female & 141 & 89.01 & 17.78 & 201 & -.517 & .207 \\
\hline General & Male & 62 & 90.35 & 15.41 & & & \\
& & & & & & &
\end{tabular}


When Table 3 is analyzed, it is seen that female pre-service teachers' average scores from internet-specific epistemological beliefs scale is $(\bar{x}=89.01)$ whilst male pre-service teachers' average scores from internet-specific epistemological beliefs scale is $(\bar{x}=90.35)$. It is seen that internet-specific epistemological beliefs of pre-service teachers do not differ depending on gender $[\mathrm{t}(201)=-.517, \mathrm{p}>.05)]$. When the sub-scales of the scale is analyzed, it is seen that there is no statistically significant difference in the sub-scales of the inventory depending on gender (certainty and source of knowledge $[\mathrm{t}(201)=-.561, \mathrm{p}>.05)]$, justification for knowing $[\mathrm{t}(201)=-.366, \mathrm{p}>.05)]$ and structure of knowledge $[\mathrm{t}(201)=.202, \mathrm{p}>.05)])$.

When Table 3 is examined, it is seen that the department which uses online information searching strategies best is English Language Teaching Department $(\bar{x}=119.83)$ whilst the department with the lowest score is preschool education department $(\bar{x}=108.21)$. When the significance of the scores between the departments is examined, it is seen that there is no statistically significant difference among departments in their scores from online information searching strategies scale $[\mathrm{F}(6,196)=2.071, \mathrm{p}>.05]$.

\section{Findings on internet-specific epistemological beliefs of pre-service teachers based on}

\section{the department}

Descriptive statistics of the internet-specific epistemological beliefs depending on the departments of pre-service teachers and ANOVA test results are presented in Table 4.

Table 4. Descriptive statistics of the scores of pre-service teachers from internet-specific epistemological beliefs scale depending on departments and anova test results

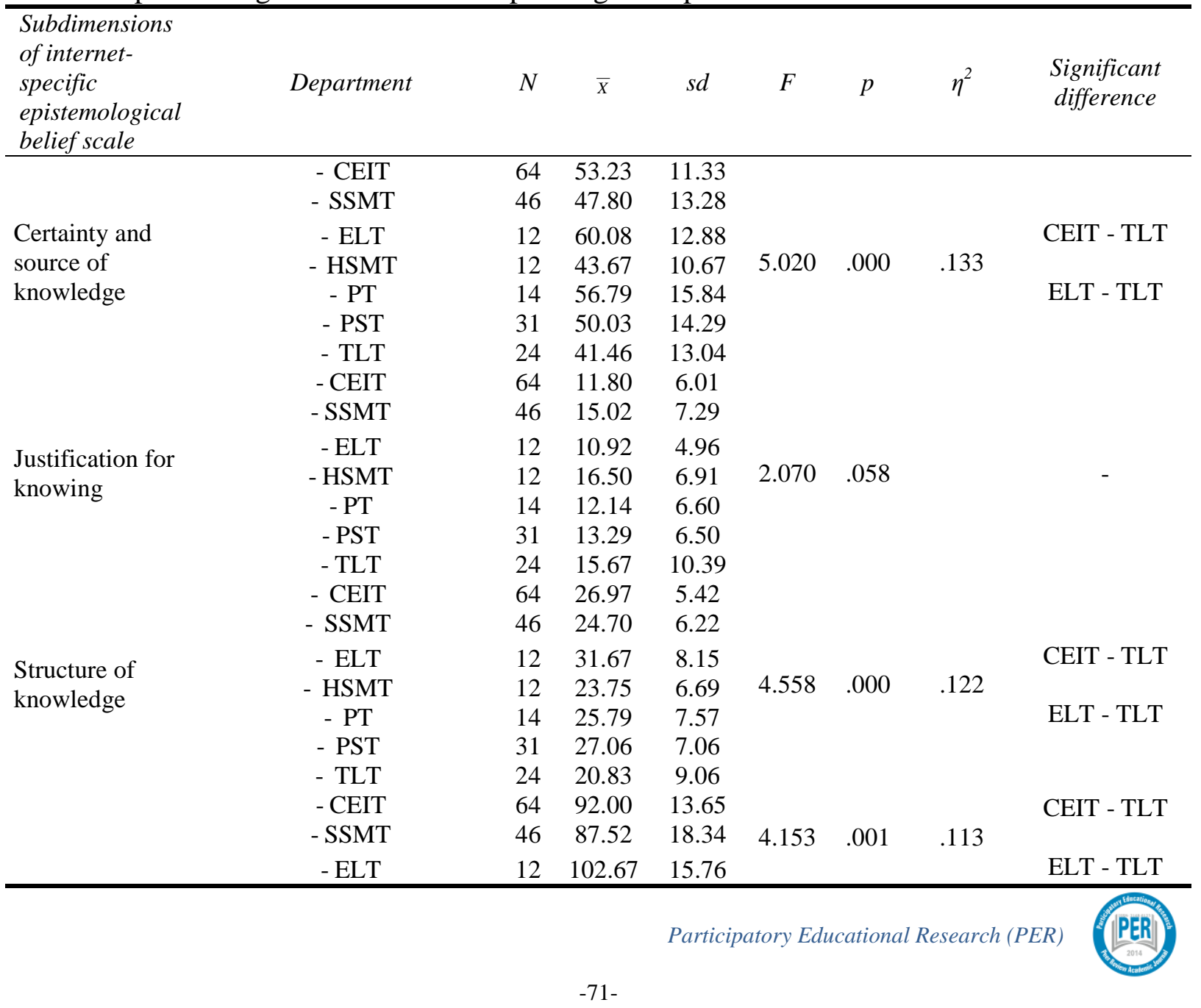




\begin{tabular}{lcccc}
\hline General & - HSMT & 12 & 83.92 & 10.94 \\
& - PT & 14 & 94.71 & 16.56 \\
& - PST & 31 & 90.39 & 18.22 \\
- TLT & 24 & 77.96 & 18.35 \\
\hline
\end{tabular}

When Table 4 is analyzed, it is seen that the highest scores from internet-specific epistemological belief scale belong to English Language Teaching Department $(\bar{x}=102.67)$ whilst the lowest scores belong to those pre-service teachers studying at High School Maths Teaching Department $(\bar{x}=83.92)$. When the significance of the difference between the departments is looked into, it is seen that pre-service teachers' averages from internet-specific epistemological belief scale is statistically significant depending on the departments they study $[\mathrm{F}(6,196)=4.153, \mathrm{p}<.05]$. To see the group creating this difference, Scheffe test was conducted. According to the results of the analysis conducted, the difference is between Computer and Instructional Technology Education and Turkish Language Teaching; and between English Language Teaching and Turkish Language Teaching. When sub-scales are analyzed, it is seen that there is a similar case between certainty and source of knowledge $[\mathrm{F}(6,196)=5.020, \mathrm{p}<.05]$ and structure of knowledge $[\mathrm{F}(6.196)=4.558, \mathrm{p}<.05]$. It is also seen that there is no statistically significant difference in justification for knowing sub-scale $[F(6,196)=2.070, p>.05]$. When the effect size is calculated in these analysis, it is seen that effect size for the overall scale is .113; whilst it is .133 for certainty and source of knowledge sub-scale and .122 for structure of knowledge sub-scale. Because these values are very close to .13 it is possible to say that the effect is average (Cohen, 1988; cited in. Bakeman, 2005).

\section{Findings on the impact of internet-specific epistemological beliefs on online}

\section{information searching strategies}

Descriptive statistics showing whether pre-service teachers' internet-specific epistemological beliefs have a significant impact on their online information searching strategy levels, in line with the fourth research problem of the study, and ANOVA test results are presented in Table 5 .

Table 5. Descriptive statistics of pre-service teachers scores from online information strategies inventory depending on their scores from internet-specific epistemological beliefs scale and anova results

\begin{tabular}{|c|c|c|c|c|c|c|}
\hline $\begin{array}{c}\text { Online information strategies } \\
\text { inventory subscales }\end{array}$ & $\begin{array}{c}\text { Internet-specific } \\
\text { epistemological beliefs } \\
\text { scale level }\end{array}$ & $N$ & $\bar{X}$ & $s d$ & $F$ & $p$ \\
\hline \multirow{3}{*}{ Disorientation } & Sophisticated & 20 & 18.05 & 3.59 & \multirow{3}{*}{.348} & \multirow{3}{*}{.707} \\
\hline & Average & 171 & 18.58 & 3.81 & & \\
\hline & Naive & 12 & 17.83 & 5.52 & & \\
\hline \multirow{3}{*}{ Evaluation } & Sophisticated & 20 & 17.75 & 4.15 & \multirow[t]{3}{*}{.130} & \multirow[t]{3}{*}{.878} \\
\hline & Average & 171 & 18.16 & 3.36 & & \\
\hline & Naive & 12 & 18.17 & 3.38 & & \\
\hline \multirow{3}{*}{ Purposeful thinking } & Sophisticated & 20 & 17.95 & 3.55 & \multirow[t]{3}{*}{.344} & \multirow[t]{3}{*}{.709} \\
\hline & Average & 171 & 17.96 & 3.55 & & \\
\hline & Naive & 12 & 17.08 & 3.75 & & \\
\hline \multirow{3}{*}{ Trial and error } & Sophisticated & 20 & 13.15 & 3.12 & \multirow[t]{3}{*}{.318} & \multirow[t]{3}{*}{.728} \\
\hline & Average & 171 & 13.29 & 2.78 & & \\
\hline & Naive & 12 & 13.92 & 2.43 & & \\
\hline \multirow{3}{*}{ Selecting main ideas } & Sophisticated & 20 & 13.40 & 3.63 & \multirow[t]{3}{*}{.903} & \multirow[t]{3}{*}{.407} \\
\hline & Average & 171 & 13.99 & 2.60 & & \\
\hline & Naive & 12 & 13.08 & 4.23 & & \\
\hline
\end{tabular}




\begin{tabular}{lcccccc}
\hline \multirow{3}{*}{ Control } & Sophisticated & 20 & 17.60 & 4.32 & 1.154 & .317 \\
& Average & 171 & 18.84 & 3.43 & & \\
\multirow{3}{*}{ Problem solving } & Naive & 12 & 19.08 & 4.03 & & \\
& Sophisticated & 20 & 13.05 & 3.43 & .306 & .737 \\
& Average & 171 & 13.20 & 2.60 & & \\
General & Naive & 12 & 12.58 & 2.78 & & \\
& Sophisticated & 20 & 110.95 & 20.54 & & \\
& Average & 171 & 114.04 & 16.54 & .368 & .692 \\
\hline
\end{tabular}

When Table 5 is examined, it is seen the average online information searching inventory scores of pre-service teachers whose internet-specific epistemological beliefs are sophisticated is 110.95; whilst the average of those whose internet-specific epistemological beliefs are average is 114.04 and the average of those whose internet-specific epistemological beliefs are naive is 111.75 . It is seen that there are differences between online information searching strategies inventory score averages depending on internet-specific epistemological beliefs. To find out if this difference is statistically significant, one-way ANOVA was conducted. When Table 5 is analyzed, it is seen that pre-service teachers' average scores from online information searching strategies inventory is not statistically significant depending on their internet-specific epistemological beliefs $[\mathrm{F}(2,200)=.368, \mathrm{p}>.05]$. In terms of sub-scales, there was no statistically significant difference found in disorientation $[F(2,200)=.348$, $\mathrm{p}>.05]$, assessment $[\mathrm{F}(2,200)=.130, \mathrm{p}>.05]$, purposeful thinking $[\mathrm{F}(2,200)=.344, \mathrm{p}>.05]$, trial and error $[\mathrm{F}(2,200)=.318, \mathrm{p}>.05]$, selecting main ideas $[\mathrm{F}(2,200)=.903, \mathrm{p}>.05]$, control $[\mathrm{F}(2,200)=1.154, \mathrm{p}>.05]$ and problem solving $[\mathrm{F}(2,200)=.306, \mathrm{p}>.05]$ sub-scales.

\section{Conclusion and Discussion}

Epistemological beliefs are considered as one of the individual factors effecting/determining the learning performances and learning strategies of learners (Hofer \& Pintrich, 1997; Tsai, 2000). With the spread of the use of internet-based learning environments and materials in education, researchers indicate that epistemological beliefs of learners towards internet are efficient in the use of these environments and materials (Bråten \& Strømsø, 2010; Strømsø et al., 2008). Tu et al. (2008) have asserted that learners' epistemological beliefs should be considered as an important factor when studying their activities on the web. In most of the studies on epistemological beliefs, the personel epistemological beliefs of the participants was discussed. However, researchers emphasize the significance of internet-specific epistemological beliefs for internet environments (Chiu et al., 2013; Kammerer et al., 2013; Karimi, 2014; Strømsø \& Bråten, 2009).

When the findings of the study which was carried out to investigate internet-specific epistemological beliefs of pre-service teachers and to look into its impact on online information searching strategies are analyzed in general, it is seen that majority of the preservice teachers' epistemological beliefs are average or in other words, unclear; whilst their online information searching strategies are developed. In their study they carried out on university students studying in different fields including medicine, engineering and social sciences, Chiu et al. (2013) found that internet-specific epistemological beliefs of the students were average/unclear. So the findings of both studies are similar in this respect. In another study carried out by Lee, Chiu, Liang and Tsai (2014) on high school students, it was found that students' internet-specific epistemological beliefs were immature/underdeveloped. In the light of this finding, it is possible to say that internet-specific epistemological beliefs improve 
with the level of education.

When pre-service teachers internet- specific epistemological beliefs were analyzed in terms of gender, it was seen that there was no statistically significant difference in epistemological beliefs based on gender. In this respect, this finding is similar to studies in which there was no statistically significant relationship was found between gender and individual epistemological beliefs (Hofer, 2000; Mason and Boscolo, 2004; Schommer et al., 1992; Schommer-Aikins et al., 2000; Strobel et al., 2004). Although there are studies in the literature revealing that gender has a significant impact on such variables as technology use (Jackson et al., 2010; Tsai and Tsai, 2010), it is seen that the case is not the same for internet-specific epistemological beliefs.

In terms of department variable, it is seen that there are significant differences between Computer Education and Instructional Technology and Turkish Language Teaching departments; and between English Language Teaching and Turkish Language Teaching Departments. It is seen that internet specific epistemological beliefs of pre-service teachers studying at Turkish Language Teaching Department are more developed compared to preservice teachers studying in other departments. The reason of this could be the fact that preservice teachers studying at Computer Education and Instructional Technology department use internet-based information sources more frequently compared to students in Turkish Language Teaching department and thus, they rely more on the sources on internet and they know better which sources to use. Because the courses in Turkish Language Teaching Department require more printed materials, they prefer books more. And the reason behind the finding that internet specific epistemological beliefs of pre-service teachers studying at English Language Teaching Department are immature/underdeveloped compared to preservice teachers studying at Turkish Language Teaching could be because the pre-service teachers studying at English Language Teaching have a better command of English language and thus, can access to more resources and information on internet. When the analyses are examined, it is seen that although the difference between internet-specific epistemological belief scores of pre-service teachers studying at Preschool Teaching and Turkish Language Teaching is bigger than the difference between internet-specific epistemological belief scores of pre-service teachers studying Computer Education and Instructional Technology and Turkish Language Teaching Departments, this is not a significant difference. In addition, because there are differences in internet-specific epistemological beliefs based on department supports the findings in the literature which focus on individiual epistemology and department. (Deryakulu and Büyüköztürk, 2005; Hammer, 1994; Palmer and Marra, 2004; Paulsen and Wells, 1998; Schommer, 1993; Strobel et al., 2004).

It is seen that the internet-specific epistemological beliefs of pre-service teachers do not have a significant effect on online information searching strategies. Although there are no studies looking into internet-specific epistemological beliefs and online information searching strategies, when the results of the study are compared to other studies in the literature it is seen that there are studies indicating that internet-specific epistemological beliefs have an impact on individuals' searching behaviors. (Tu et al., 2008; Mason and Ariasi, 2010; Kammerer and Gerjets, 2012; Tsai et al., 2011). However, it is seen that in the aforementioned studies indivduals' searching behaviors were observed through such methods as eye fixation and instead of examining cognitive and that these studies focus more on searching behaviors rather than metacognitive strategies that individuals use during the searching process.When the dimensions of Tsai (2009)'s online information searching strategies (disorientation, evaluation, purposeful thinking, selecting main ideas, trial and error, 
control and problem solving) are examined, it is seen that these dimensions could be related to self-regulation behaviors in information searching process. In this respect, it is more convenient to compare the findings of the study with studies examining the self-regulation learning behaviors in information searching process. In this sense, it is possible to say that the results of this study are similar to Chiu et al.'s (2013) study looking into the relationship between internet-specific epistemological beliefs and self-regulatory learning behaviors (planning, control, monitoring, reflecting). Chiu et al. (2013) indicate that there is no direct significant relationship between internet-specific epistemological beliefs and self-regulatory learning behaviors. In other words, there is no guarantee that individuals having mature/developed internet-specific epistemological beliefs will show self-regulation behaviors in internet-based learning and searching processes.

According to researchers the possibility for those students with developed/ mature epistemological beliefs to adopt the preparatory process of self-regulated learning (defining tasks, setting goals and making search) is lower. Similarly, Strømsø and Bråten (2010) state that having developed/mature epistemological beliefs in internet-based learning process does not mean that you will be interested in self-regulation strategies. According to the researchers, students with developed/mature epistemological beliefs are more sceptical about the correctness of the information on internet and about the richness of the details, but these students are less enthusiastic about showing self-regulatory learning behaviors in the correctness of the information and richness of the details.

From a different point of view, the reason behind the fact that internet-specific epistemological beliefs do not create a significant effect on online information searching strategies is that the pre-service teachers in the study group have developed searching strategies and thus, they can access more convenient, reliable sources as a result of online searching. Therefore, students who can find the results they look for will have the belief that internet is comprehensive and reliable source of information and this could cause them to exhibit an average/unclear epistemological belief state about internet.This view could be confirmed with other study results in the literature. Kammerer and Gerjets (2012) also found that students who accept that internet incorporates correct information while they are searching online, or in other words students with underdeveloped epistemological beliefs, consider many options in their search performances and get better search results. In other words, individuals with underdeveloped epistemological beliefs have tendency to show selfregulatory behaviors, and since those students with developed epistemological beliefs are more sceptical about the sources of information on internet, they do not show self-regulatory behaviors. Similarly, Bråten et al. (2005) indicate that those with underdeveloped epistemological beliefs have the tendency to examine the details of internet-based sources of information and relevant information. Bråten et al. (2005) indicate that the functions of having developed epistemological beliefs could differ in traditional learning environments and internet-based learning environments. Pieschl et al. (2008) state that the impact of having developed epistemological beliefs should be assessed based on the context and practices of learning; and that depending on contextual conditions the functions of developed epistemological beliefs could differ. For instance, as for Elby and Hammer (2001) the change in study topics and learning activities could also cause to a change in epistemological beliefs. According to researchers the process of learning physics is different from the process of learning the capitals of countries. If the student has an anxiety to get a grade and if the topic allows memorizing, students might not use their epistemological beliefs even if they have developed epistemological beliefs and might have the tendency to prefer to memorize capital city names. Therefore, Chiu et al. (2013) emphasize that future studies on internet specific 
epistemological beliefs should focus based on field of specialization. In fact, the results of the current study reveal that department variable is an efficient factor on internet-specific epistemological beliefs.

As a result, it can be said that internet specific epistemological beliefs do not have a significant impact on individuals' information searching strategies on internet-based environments; in other words, having developed epistemological beliefs do not guarantee the correct strategy use in information searching process. However, it can also be concluded that individuals' internet specific epistemological beliefs could differ based on the department they study.

Researchers indicate the importance of having sophisticated epistemological beliefs in order to improve online information searching strategies of the individuals, evaluate the convenience of the informed found and decide on whether it is true and up-to-date (Mason \& Boldrin, 2008; Tu et al., 2008; Tsai et al., 2011; Wu \& Tsai, 2005). Yet, the findings of this study indicate that most of the pre-service teachers have an average level of internet-specific epistemological beliefs. In the light of the findings of the study, it is important to take measures in teacher education programmes to develop internet-specific epistemological beliefs of pre-service teachers to a sophisticated level. First of all, it is necessary to provide trainings and take measures towards improving internet-literacy skills of pre-service teachers (Chiu et al., 2013). Particularly in computer classes taught in teacher education programmes, it is necessary to equip pre-service teachers with required knowledge and skills on developing internet-literacy and making efficient search on internet, and on accessing internet-based information sources and identifying true and up-to-date sources. Such trainings should aim at equipping pre-service teachers with required knowledge and skills on using internet search engines, databases, making search in images, news, videos, maps etc. Considering the fact that forming epistemological beliefs is a process, equipping learners with this knowledge and skills starting at a young age become more important. Researches reveal that individuals need support in showing developed epistemological belief and critical thinking in internet-based learning and information searching processes. Therefore, researchers indicate that providing metacognitive guidance in this process will make it easier for individuals to show metacognitive skills (Hofer 1994; Schommer 1990; Tsai and Chuang, 2005). Individuals could be provided with synchronous and asynchoronous metacognitive guidance in internetbased learning and information searching processes.

\section{Suggestions}

This study examined internet-specific epistemological beliefs of pre-service teachers related to the courses they took in the departments they study. The results of this study do not reveal the internet searching behaviors of those individuals in the study group for such purposes as health, world knowledge and shopping. Epistemological beliefs related to such variables should be separately studied. Teachers' internet-specific epistemological beliefs should be examined in future studies. Because teachers will use internet in choosing the content and materials they will use in their classes, it is believed that internet-specific epistemological beliefs could differ from pre-service teachers. This should be studied. In addition, looking into the internet-specific epistemological beliefs of the students studying in departments other than teacher training programmes of the universities will be useful in terms of making generalizations and revealing differences. The data in this study was collected through a scale and based on the statements of the pre-service teachers. However, this data 
might not completely reflect the strategies that pre-service teachers use in the process of information searching and their searching performance. Therefore, supporting the findings of the studies carried out through using aforementioned scales with qualitative research findings (f.e with data collected through such methods as eye fixation technology, think aloud, database performance records etc.) will help for a better understanding of the results. In addition, the effect of internet-specific epistemological beliefs on cognitive load in web-based learning environments and on surfing strategies could be examined. And the effect of using adaptable learning environments and getting customizable search results on internet-specific epistemological beliefs could be studied in future studies.

\section{References}

Aşkar, P., \& Mazman, S. G. (2013). Adaptation of online information searching strategy inventory into turkish. Education and Science, 38(168).

Bakeman, R. (2005). Recommended effect size statistics for repeated measures designs. Behavior research methods, 37(3), 379-384.

Bråten, I., \& Strømsø, H. I. (2004). Epistemological beliefs and implicit theories of intelligence as predictors of achievement goals. Contemporary Educational Psychology, 29(4), 371-388.

Bråten, I., \& Strømsø, H. I. (2005). The relationship between epistemological beliefs, implicit theories of intelligence, and self-regulated learning among Norwegian postsecondary students. British Journal of Educational Psychology, 75(4), 539-565.

Bråten, I., Strømsø, H. I., \& Samuelstuen, M. S. (2005). The relationship between Internetspecific epistemological beliefs and learning within internet technologies. Journal of Educational Computing Research, 33(2), 141-171.

Bråten, I., \& Strømsø, H. I. (2010). When law students read multiple documents about global warming: Examining the role of topic-specific beliefs about the nature of knowledge and knowing. Instructional Science, 38(6), 635-657.

Chiu, Y. L., Liang, J. C., \& Tsai, C. C. (2013). Internet-specific epistemic beliefs and selfregulated learning in online academic information searching. Metacognition and Learning, 8(3), 235-260.

Deryakulu, D. (2002). The relationships among locus of control, epistemological beliefs and instructional material comprehension monitoring types and levels. Hacettepe University Journal of Education, 22(22).

Deryakulu, D., \& Büyüköztürk, Ş. (2005). The re-examination of the epistemological beliefs questionnaire's factor structure: comparing epistemological beliefs in terms of gender and program type. Ĕgitim Araştırmaları, 18, 57-70.

Elby, A., \& Hammer, D. (2001). On the substance of a sophisticated epistemology. Science Education, 85(5), 554-567.

Fraenkel, J. R., \& Wallen, N. E. (2006). How to design and evaluate research in education. Mc Grawall Hill.

Hammer, D. (1994). Epistemological beliefs in introductory physics. Cognition and Instruction, 12(2), 151-183.

Hartley, K., \& Bendixen, L. D. (2001). Educational research in the internet age: Examining the role of individual characteristics. Educational researcher, 30(9), 22-26.

Hofer, B. K. (1994). Epistemological beliefs and first-year college students: Motivation and cognition in different instructional contexts. Paper presented at the annual meeting of the American Psychological Association, Los Angeles. 
Hofer, B. K., \& Pintrich, P. R. (1997). The development of epistemological theories: Beliefs about knowledge and knowing and their relation to learning. Review of Educational Research, 67(1), 88-140.

Hofer, B. K. (2000). Dimensionality and disciplinary differences in personal epistemology. Contemporary Educational Psychology, 25(4), 378-405.

Hofer, B. K., \& Pintrich, P. R. (eds). (2002). Personal epistemology: The psychology of beliefs about knowledge and knowing. Mahwah, NJ: Erlbaum.

Jackson, L. A., von Eye, A., Fitzgerald, H. E., Zhao, Y., \& Witt, E. A. (2010). Self-concept, self-esteem, gender, race and information technology use. Computers in Human Behavior, 26(3), 323-328.

Kammerer, Y., \& Gerjets, P. (2012). Effects of search interface and Internet-specific epistemic beliefs on source evaluations during Web search for medical information: an eye-tracking study. Behaviour \& Information Technology, 31(1), 83-97.

Kammerer, Y., Bråten, I., Gerjets, P., \& Strømsø, H. I. (2013). The role of internet-specific epistemic beliefs in laypersons' source evaluations and decisions during Web search on a medical issue. Computers in Human Behavior, 29(3), 1193-1203.

Karimi, M. N. (2014). EFL students' grammar achievement in a hypermedia context: Exploring the role of internet-specific personal epistemology. System, 42, 1-11.

Karaoglan Yilmaz, F. G., Yilmaz, R., Teker, N., \& Keser, H. (2014). Prediction of internet addiction of university students based on various variables. World Journal on Educational Technology, 6(1).

Kılıç Çakmak, E., Karaoğlan Yılmaz, F.G., \& Y1lmaz, R. (2015). Adaptation of internetspecific epistemological belief scale. Education Technology Theory and Practice, 5(1), $55-71$.

Lee, M. H., \& Tsai, C. C. (2005). Exploring high school students' and teachers' preferences toward the constructivist Internet-based learning environments in Taiwan. Educational Studies, 31(2), 149-167.

Lee, W. C., Chiu, Y. L., Liang, J. C., \& Tsai, C. C. (2014). Exploring the structural relationships between high school students' Internet-specific epistemic beliefs and their utilization of online academic help seeking. Computers in Human Behavior, 36, 391400.

Mason, L., \& Boscolo, P. (2004). Role of epistemological understanding and interest in interpreting a controversy and in topic-specific belief change. Contemporary Educational Psychology, 29(2), 103-128.

Mason, L., \& Boldrin, A. (2008). Epistemic metacognition in the context of information searching on the Web. In M. S. Khine (Ed.), Knowing, knowledge and beliefs: Epistemological studies across diverse cultures (pp. 377-404). NY: Springer.

Mason, L., \& Ariasi, N. (2010). Critical thinking about biology during web page reading: Tracking students' evaluation of sources and information through eye fixations. In L. Verschaffel, E. De Corte, T. de Jong, \& J. Elen (Eds.), Use of external representations in reasoning and problem solving: Analysis and improvement (pp. 55-73). London: Routledge.

Mason, L., Ariasi, N., \& Boldrin, A. (2011). Epistemic beliefs in action: Spontaneous reflections about knowledge and knowing during online information searching and their influence on learning. Learning and Instruction, 21(1), 137-151.

Muis, K. R. (2004). Personal epistemology and mathematics: A critical review and synthesis of research. Review of Educational Research, 74(3), 317-377.

Palmer, B., \& Marra, R. M. (2004). College student epistemological perspectives across knowledge domains: A proposed grounded theory. Higher Education, 47(3), 311-335. 
Pieschl, S., Stahl, E., \& Bromme, R. (2008). Epistemological beliefs and self-regulated learning with hypertext. Metacognition and Learning, 3(1), 17-37.

Schommer, M. (1990). Effects of beliefs about the nature of knowledge on comprehension. Journal of Educational Psychology, 82(3), 498-504.

Schommer, M., Crouse, A., \& Rhodes, N. (1992). Epistemological beliefs and mathematical text comprehension: Believing it is simple does not make it so. Journal of Educational Psychology, 84(4), 435.

Schommer, M. (1993). Epistemological development and academic performance among secondary students. Journal of Educational Psychology, 85(3), 406.

Schommer-Aikins, M., Mau, W. C., Brookhart, S., \& Hutter, R. (2000). Understanding middle students' beliefs about knowledge and learning using a multidimensional paradigm. The Journal of Educational Research, 94(2), 120-127.

Schommer-Aikins, M., Duell, O. K., \& Hutter, R. (2005). Epistemological beliefs, mathematical problem-solving beliefs, and academic performance of middle school students. The Elementary School Journal, 105(3), 289-304.

Strobel, J., Cernusca, D., \& Jonassen, D. H. (2004). Different majors-different epistemological beliefs. Academic Exchange Quarterly, 22(3), 208-211.

Strømsø, H. I., Bråten, I., \& Samuelstuen, M. S. (2008). Dimensions of topic-specific epistemological beliefs as predictors of multiple text understanding. Learning and Instruction, 18(6), 513-527.

Strømsø, H. I., \& Bråten, I. (2009). Beliefs about knowledge and knowing and multiple-text comprehension among upper secondary students. Educational Psychology, 29, 425445.

Strømsø, H. I. ve Bråten, I. (2010). The role of personal epistemology in the self-regulation of internet-based learning. Metacognition and Learning, 5(1), 91-111.

Tsai, M. J., \& Tsai, C. C. (2003). Information searching strategies in web-based science learning: The role of Internet self-efficacy. Innovations in Education and Teaching International, 40(1), 43-50.

Tsai, C. C., \& Chuang, S. C. (2005). The correlation between epistemological beliefs and preferences toward Internet-based learning environments. British Journal of Educational Technology, 36(1), 97-100.

Tsai, M. J. (2009). Online information searching strategy inventory (OISSI): A quick version and a complete version. Computers \& Education, 53(2), 473-483.

Tsai, M. J., \& Tsai, C. C. (2010). Junior high school students' Internet usage and selfefficacy: A re-examination of the gender gap. Computers \& Education, 54(4), 11821192.

Tsai, P. S., Tsai, C. C., \& Hwang, G. J. (2011). The correlates of Taiwan teachers' epistemological beliefs concerning Internet environments, online search strategies, and search outcomes. The Internet and Higher Education, 14(1), 54-63.

Tsai, C. C. (2000). Relationships between student scientific epistemological beliefs and perceptions of constructivist learning environments. Educational Research, 42(2), 193205.

Tu, Y. W., Shih, M., \& Tsai, C. C. (2008). Eighth graders' web searching strategies and outcomes: The role of task types, web experiences and epistemological beliefs. Computers \& Education, 51(3), 1142-1153.

Wu, Y. T., \& Tsai, C. C. (2005). Information commitments: evaluative standards and information searching strategies in web-based learning environments. Journal of Computer Assisted Learning, 21(5), 374-385. 
Yang, F. Y. (2005). Student views concerning evidence and the expert in reasoning a socio-scientific issue and personal epistemology. Educational Studies, 31(1), 65-84. 